\title{
How Responsible Leadership Motivates Employees to Engage in Organizational Citizenship Behavior for the Environment: A Double-Mediation Model
}

\author{
Zhiyong Han ${ }^{1,2, *}$, Qun Wang ${ }^{1,3}$ and Xiang Yan ${ }^{1,4}$ \\ 1 Business School, Hohai University, Nanjing 211100, China; wqun@hhu.edu.cn (Q.W.); \\ yanxiang@hhu.edu.cn (X.Y.) \\ 2 School of Business Administration, Anhui University of Finance and Economics, Bengbu 233030, China \\ 3 Jiangsu Provincial Collaborative Innovation Center of World Water Valley and Water Ecological Civilization, \\ Nanjing 211100, China \\ 4 Business School, Yancheng Teachers University, Yancheng 224007, China \\ * Correspondence: hzyong@aufe.edu.cn
}

Received: 15 December 2018; Accepted: 22 January 2019; Published: 24 January 2019

\begin{abstract}
By collecting and analyzing sample from 384 employees in China, this study explored relationship between responsible leadership and organization citizenship behavior for the environment (OCBE) with structural equation model (SEM). The results are as follows: (1) responsible leadership is positively related to organization citizenship behavior for the environment. (2) responsible leadership has positive effects on both autonomous and external environmental motivation. (3) autonomous and external environmental motivation have a multiple-mediate role in the relationship between responsible leadership and organization citizenship behavior for the environment. Finally, this paper discusses the management implications of the research results and the future research direction.
\end{abstract}

Keywords: responsible leadership; autonomous motivation; external motivation; organizational citizenship behavior for the environment

\section{Introduction}

With the aggravation of environmental problem such as global climate change and biodiversity reduction, enterprises are subject to higher expectations regarding ecological behavior and corporate management's contribution to sustainable development has attracted the attention of academics, managers and policymakers [1-3]. In addition, green finance, green supply chains and green human resources have become strategic choices for enterprises seeking long-term development [4]. In corporate contributions of sustainable development, various stakeholders (meso-level enterprises, government and nonprofit organizations as well as individuals and teams in microlevel organizations) play an important role [5]. However, scholars have tended to focus on corporate environmental protection behavior from strategic and operational perspectives while neglecting the basic importance of corporate employees' environmental protection behavior [6].

Employees are important stakeholders in an enterprise and the environmental protection behavior of enterprises depends highly on their participation. In addition, interpersonal interaction among individual employees helps promote sustainable management at the macro level [7]. Therefore, it is valuable to examine corporate environmental protection behavior at the employee level. Research in this area focuses on what is termed organizational citizenship behavior directed toward the environment (OCBE). OCBE refers to the environmental practices of employees within their organizations. These practices are often not rewarded or required by the organization's formal reward 
system. However, they represent a useful supplement to the environmental protection behavior of the general public and enterprise green development strategies [8]. Specifically, individual employees engage in environmentally friendly behavior in their workplaces and implement environmentally friendly concepts there. For example, save paper, decrease energy consumption, help colleagues engage in environmental protection behavior or make recommendations regarding environmental protection to organization management. Such practices are typically consistent with the organization's green strategy and institutional requirements [9].

Given the significant impact of employee environmental protection behavior on corporate environmental protection outcomes, a number of studies have sought to determine the factors that influence such OCBE. These factors include the organizational support perceived by the employees [10,11], employee self-responsibility with respect to environmental protection [12], corporate environmental protection measures at the organizational level [13], corporate environmental concerns [14] and corporate environmental attitudes [10]. Among these factors, leadership behavior functions as an important link between the organization and the employees and exerts a profound effect on OCBE. Studies have confirmed that ethical leadership [12], and leadership support for environmental protection [15] enhance OCBE.

Such leadership behavior primarily affects OCBE through the interaction of the leadership and employees within the enterprise and has been examined from the dual perspectives of leadership and employees. Leadership interaction with other enterprise stakeholders has been neglected. The fundamental purpose of OCBE, which is behavior exercised outside regular work duties, is to improve the social ecological environment by improving the environmental protection performance of the enterprise. Therefore, when discussing the influence of leadership behavior on employee environmental protection behavior, one must consider the roles of various stakeholders. Here, responsible leadership is leadership behavior that focuses on the interests of the business as well as other stakeholders. Responsible leadership combines leadership and social responsibility, considers the interests of various stakeholders (including employees) and strives to integrate economic, social and ecological benefits. This view is in line with the thinking on OCBE. Previous studies have found that responsible leadership improves employees' green behavior at work [16] and organizational citizenship behavior by enhancing employees' felt obligation [17]. However, the relationship between responsible leadership and OCBE as well as the mechanisms of that relationship have rarely been addressed. Therefore, our study contributes to fulfill the research gap in the literature on responsible leadership and OCBE.

\section{Theoretical Basis and Research Hypothesis}

\subsection{Responsible Leadership}

In recent years, economic globalization, organizational networking and employee diversification have become increasingly prominent. To make organizations successful, leaders must pay attention to not only the profit return of shareholders but also corporate social responsibility [18]. Responsible leadership represents a powerful response to the diverse needs and challenges of the complex stakeholder society. The study of responsible leadership originates in social relations and ethical theory and is a relational and ethical phenomenon that occurs in the social interaction process [19]. Responsible leadership occupies a central position in the stakeholder relation network and plays a variety of roles (e.g., housekeeper, citizen, dreamer) [19]. It reaches agreement on stakeholder demands through democratic negotiation and discourse [20]. Responsible leadership involves the ability to build and sustain good relations among all stakeholders by addressing four types of driving force: protection, acquisition, connection and understanding [21].

The key difference between responsible leadership and other traditional forms of leadership (e.g., reformative leadership, ethical leadership, service leadership or authentic leadership) is that responsible leadership focuses on society and the environment, sustainable value creation and positive 
change [22]. Traditional leadership (e.g., ethical leadership) overemphasizes its influence and does not adequately recognize the surrounding environment on which the leadership depends and the other stakeholders with which it interacts. In addition, such leadership forms ignore the responsibility dimension, which has been a focus of studies on responsible leadership [23]. Therefore, responsible leadership transcends the binary leadership-employee relationship that has been the focus of traditional leadership studies and emphasizes multiple leader-stakeholder relationships, paying attention to not only the interests of shareholders in decision-making but also the needs of multiple stakeholders.

\subsection{Relationship between Responsible Leadership and OCBE}

OCBE refers to the environmental protection practices performed by employees within an organization that are often not rewarded or required by the organization's formal reward system. OCBE is a useful supplement to the environmental protection behavior of citizens and the green development strategy of the enterprise [8]. Employees saving paper in the workplace, helping reduce energy consumption, assisting colleagues to practice green behavior, and making environmental protection recommendations to their organization are typical examples of OCBE. According to the theory of social learning, individuals can guide their own behavior by observing and imitating others [24]. Responsible leadership focuses on the interests of various stakeholders related to the business and exchanges information and opinions with employees when communicating with them. Through such behavior, responsible leadership transmits relevant information to employees by interacting with them, and the subordinates gradually accept and internalize the values of the leadership through observing and imitating its behavior. Previous studies have revealed that responsible leadership significantly affects employee organizational citizenship behavior [25], job satisfaction [26], resignation intention [27], job performance [28], organizational commitment [20,29] and unethical behavior [26].

Responsible leadership pays attention to not only ethical issues but also building relationships with stakeholders and establishing long-term goals. OCBE reflects the individual's ethical belief and the individual's effort to balance the relationship between human society and nature while enhancing sustainable management, which is consistent with the core ideas of responsible leadership. According to Stahl and de Luque, a responsible leader encourages companies to develop codes of conduct and management measures regarding environmental protection and to clarify which behaviors are acceptable or unacceptable [30]. In addition, responsible leadership can enhance employee performance in extra-role behaviors, i.e., organizational citizenship behavior. it cares about the interests of stakeholders in and outside the organization and strives to make decisions that consider the interests of all parties. Such behavior inspires employees to actively imitate and to learn to seize the initiative in caring for others and in playing various extra-role behaviors. That is, through the role model effect, responsible leadership effectively enhances employee organizational citizenship behavior [20]. OCBE is voluntary extra-role behavior, and here too, the behavior of responsible leadership can serve as a model. In the important interpersonal interaction between leadership and subordinates, the leadership's concern for environmental protection and the display of environmental protection behavior set examples for employees. Thus, responsible leadership combines leadership and social responsibility, considers the interests of many stakeholders (including employees) and strives to integrate economic, social and ecological benefits-behavior that is in line with the idea of OCBE.

In summary, we believe that responsible leadership is ethically concerned about its responsibility for the environment, strives to find a balance between society and nature and encourages employees to demonstrate OCBE through management measures and by serving as a role model.

$\mathbf{H}_{\mathbf{1}}$. Responsible leadership has a positive impact on OCBE. 


\subsection{Relationship between Responsible Leadership and Autonomous Motivation}

In this study, we propose that responsible leadership increases the autonomous motivation to protect the environment. Regarding autonomous motivation, individuals often engage in activities that are consistent with their inner self [31-33]. These activities primarily include those that are in line with their values and goals and are interesting and pleasant [32]. In the organizational context, leadership passes on its values by providing exemplary role models, while employees internalize the displayed values through observation and perceptual learning [34]. Such internalization can increase employee self-expression. Responsible leadership is concerned about the responsibility of individuals for the wellbeing of society and the environment and may raise the goals of sustainable management. For example, it may elaborate environmental objectives through emphasizing high-level values (i.e., creating a better planet for future generations, working to improve human health). Employees can accept and internalize the values expressed by the leadership, and in this manner, their engagement in environmental activities becomes more meaningful [35-37]. Additionally, responsible leadership encourages employees to participate in decision-making and conveys the idea that the organization values employee opinion, which provides employees with a sense of psychological ownership that meets their intrinsic needs and motivates them to perform their jobs well [29]. Previous studies have confirmed that responsible leadership's trust in environmental goals, emphasis on new approaches to solving environmental problems and the ability to develop each employee's capability may enhance the employee's ability to recognize and solve environmental problems [38,39]. Ultimately, the employees will possess environmentally friendly values and goals, which gives rise to a sense of autonomy or personal will. In addition, employees may agree with leadership regarding the goals of environmentally sustainable management. Therefore, responsible leadership encourages employees to align environmental protection behavior with their own interests, values and goals, thereby encouraging their autonomous motivation.

$\mathbf{H}_{\mathbf{2 a}}$. Responsible leadership has a positive impact on employee autonomous motivation.

\subsection{Relationship between Responsible Leadership and OCBE-Mediating Role of Autonomous Motivation}

Responsible leadership promotes autonomous motivation, which in turn promotes OCBE. According to the theory of self-determination, an individual's behavior is primarily influenced by autonomous motivation and extrinsic motivation, and the choices individuals make are based on their needs and their ideas with respect to the environment [40]. Therefore, employees who engage in OCBE primarily consider that engaging in environmental protection behavior can make them feel satisfied and that such behavior is rewarded, encouraged and supported. Graves et al. (2013) found that employee environmental protection behavior results from a combination of autonomous motivations and external motivations [41]. Environmental activities triggered by autonomous motivations are consistent with the individual employee's values, goals and interests $[32,42,43]$. Therefore, even if the organization does not reward OCBE, employees will voluntarily engage in it. A study on student environmental protection behavior (e.g., reusing, recycling, purchasing environmentally friendly products or saving energy) revealed that the students' autonomous environmental protection motivation is positively correlated with their environmental protection behavior [44,45]. Previous studies have also shown that employees' autonomous motivations prompt them to engage in environmentally friendly behavior [46]. Through internalizing the values of responsible leadership and aligning themselves with the environmental goals of such leadership, employees enhance their autonomous motivation, which in turn further prompts the employees to participate in OCBE. In summary, we believe that responsible leadership prompts employees to engage in OCBE by increasing their autonomous motivation.

$\mathbf{H}_{\mathbf{2} \mathbf{b}}$. Autonomous motivation mediates the relationship between responsible leadership and OCBE. 


\subsection{Relationship between Responsible Leadership and External Motivation}

Responsible leadership can provide the employee not only autonomous motivation but also external motivation. In terms of external motivation, individuals' behaviors stem from a belief that they must or should take action [31-33]. For example, individuals engage in certain acts because they want to meet operational requirements (e.g., environmental management system requirements), obtain a certain reward or avoid punishment [41]. Studies have demonstrated that responsible leadership may use external incentives and motivations [47,48]. Environmentally responsible leadership can use external rewards and incentives to motivate employee interest. In addition, certain elements of environmentally responsible leadership may enhance external motivation. For example, environmentally responsible leadership attaches importance to developing the capabilities of employees and promotes external motivation through improving competitiveness [41]. Responsible leadership extends its concern to various stakeholders, such as employees, society and the environment, and may actively promote an environmentally responsible management model in the organization, e.g., by establishing an environmental management system or advocating and establishing an environmental protection behavior reward or punishment system. Thus, employees may engage in environmental protection behavior in response to job requirements or rewards [9,49]. In addition, if responsible leadership demonstrates an exemplary image of environmental friendliness, it can inspire employees to learn and imitate that attitude to obtain the leadership's recognition and encouragement. As a result, employees may exhibit more environmental protection behavior. Thus, we propose the following hypothesis:

$\mathbf{H}_{3 \mathbf{a}}$. Responsible leadership has a positive impact on employee external motivation.

\subsection{Relationship between Responsible Leadership and OCBE-Mediating Role of External Motivation}

Although OCBE is primarily generated by employee autonomous motivation, we also examine the impact of external motivation on OCBE. Organizations may implement environmental management systems and incentive programs. Such external motivation inevitably affects employee engagement in environmental protection behavior [9,49]. Even if OCBE is not recognized or rewarded by the organization's formal reward system, external incentives outside that system (e.g., the leadership's encouragement, exemplary moral conduct) will affect employee environmental protection behavior. Employees hope to be recognized by the leadership by engaging in environmental protection behavior and align their behavior with that of the leadership to avoid psychological moral punishment. Occasionally, employees engage in OCBE to return a favor to the leadership or to obtain its support [11,14]. In addition, it was found that increased support from the leadership, the organization and the organizational commitment perceived by the employees may prompt them to return a favor out of an obligation to protect the environment and thus to engage in OCBE [13]. A negative attitude of the company towards the environment may cause certain employees to feel guilty, and those with a sense of moral responsibility may determine to compensate for environmental losses by increasing their environmental protection investment [50]. They may also adopt OCBE to avoid what they consider immoral behavior with respect to the environment. Responsible leadership will approve, recognize and support employee environmentally friendly behavior, which represents an external motivation for employees to engage in OCBE. Additionally, responsible leadership advocates responsibility for and developing a harmonious relationship with the environment and adheres to the concept of sustainable development. This attitude can prompt the development of environmentally friendly ethics in employees, who may become more involved in OCBE to remain consistent with the environmental ethics of the leadership and avoid moral punishment. In summary, we believe that responsible leadership promotes employee external motivation by approving, supporting, encouraging or establishing environmental ethics models, thus further promoting OCBE.

\section{$\mathbf{H}_{3 \mathbf{b}}$. External motivation mediates the relationship between responsible leadership and OCBE.}

The overall study model is shown in Figure 1. 


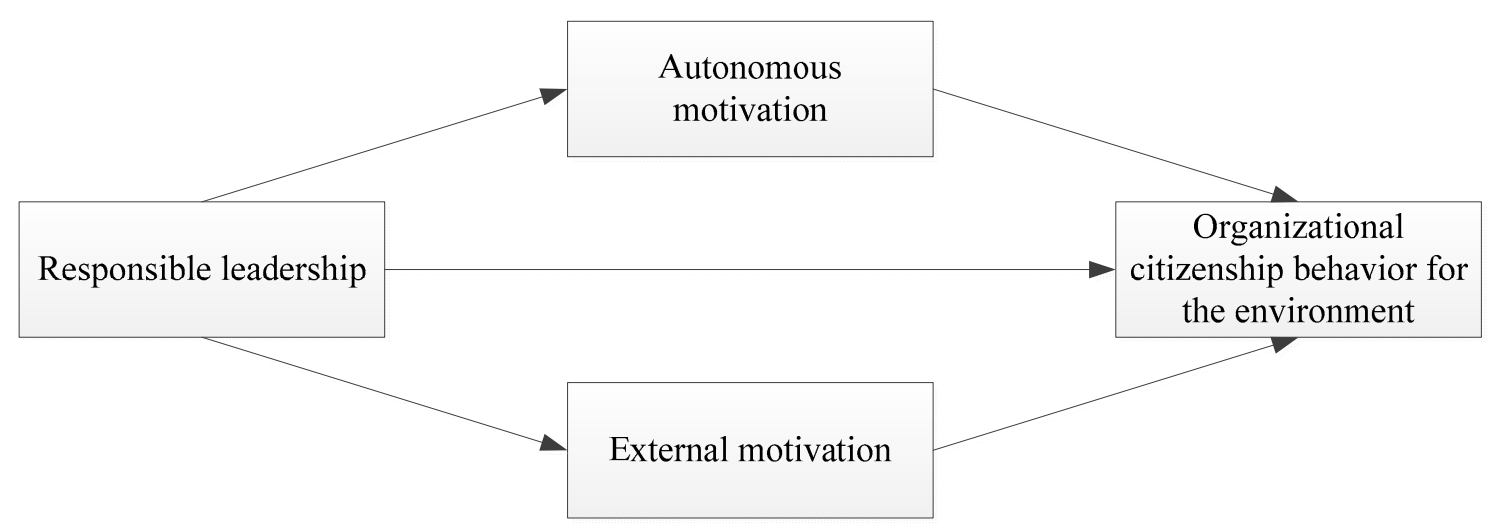

Figure 1. Hypothesized Model.

\section{Research Methods}

\subsection{Sample}

The sample was composed of 384 employees of different industries, such as banking, insurance, medicine, teaching and services in China. About $49.0 \%$ of the respondents were male, the sample included a wide range of ages, about $39.3 \%$ of the respondents were between 30 and 39 years old, and $56.3 \%$ of the sample had a bachelor's degree, and their work experience ranged from 1 to 20 years. About $31.8 \%$ of the respondents worked in their organizations for 11-20 years.

\subsection{Measurement}

This study involved four conceptual variables and demographic variables of employees (as control variables). The four conceptual variables were measured with 5-point Likert scale $(1=$ strongly disagree, $5=$ very agreed).

Responsible leadership. This study adopted the scale developed by Voegtlin (2011), which includes five items. The representative items were: "my direct superior weighs different stakeholder claims before making a decision" and "my direct superior tries to achieve a consensus among the affected stakeholders." In order to let the respondents understand the stakeholders clearly, we made the following statement in the questionnaire: the stakeholders mainly include customers, suppliers, government, natural environment and so on. In this study, the Cronbach's alpha for this scale was 0.847 .

OCBE. This study adopted the scale developed by Temminck et al (2015), which includes seven items. The representative items were: "I try to make innovative environmental suggestions to improve the organization", "I inform management of potentially environmentally irresponsible policies and practices" and "I suggest revisions to work practices to achieve the organization's environmental objectives". In this study, the Cronbach's alpha for this scale was 0.952 .

Autonomous motivation. This study adopted the scale developed by Graves et al (2013), which includes six items. The representative items were: I would engage in green behaviors at work because it allows me to achieve goals I consider important, it fits my own values, I enjoy it. In this study, the Cronbach's alpha for this scale was 0.938 .

External motivation. This study adopted the scale developed by Graves, et al (2013), which including three items. The representative items were: I would engage in green behaviors at work because: "I will be rewarded for doing this", "I am hired to do this". In this study, the Cronbach's alpha for this scale was 0.775 .

Control variables. This study control demographic variables (gender, age, education, organizational tenure). We use dummy variables to measure gender: 1 for male and 2 for female. Age is measured: 20 years or younger, 25-29 years old, 30-39 years old, 40-49 years old, 50 years old and above. Organizational tenure is measured in five categories: less than one year, 1-5 years, 6-10 years, 
11-20 years, and more than 20 years. The level of education is measured in five categories: technical secondary school and below, junior college, undergraduate, master's degree and doctoral degree.

\section{Results}

\subsection{Confirmatory Factor Analysis}

This study measured four main variables: responsible leadership, autonomous motivation, external motivation and OCBE. In this paper, confirmatory factor analysis tests are carried out using AMOS21.0 to estimate the discriminative validity between variables. As shown in Table 1, the model shows an acceptable fit $\left(\chi^{2}=470.325, \mathrm{df}=178\right.$; RMSEA $\left.=0.065, \mathrm{CFI}=0.955, \mathrm{IFI}=0.955\right)$. All the standardized factor loadings in model 1 are above $0.7(p<0.001)$, which indicates that the conformation measurement has good aggregation validity.

Table 1. Comparison of Measurement Models.

\begin{tabular}{lccccc}
\hline \multicolumn{1}{c}{ Model } & $\boldsymbol{x}^{\mathbf{2}}$ & $\boldsymbol{d f}$ & IFI & CFI & RMSEA \\
\hline 1. Four-factor model & 470.325 & 178 & 0.955 & 0.955 & 0.065 \\
2. Three-factor model & 654.500 & 179 & 0.927 & 0.926 & 0.083 \\
3. Three-factor model & 727.065 & 179 & 0.916 & 0.915 & 0.089 \\
4. Two-factor model & 769.186 & 180 & 0.909 & 0.909 & 0.092 \\
5. Single-factor model & 788.153 & 184 & 0.907 & 0.907 & 0.093 \\
\hline
\end{tabular}

Note: 1 = Responsible leadership, autonomous motivation, external motivation and OCBE; 2 = responsible leadership, autonomous motivation + external motivation, OCBE; $3=$ responsible leadership $+\mathrm{OCBE}$, autonomous motivation, external motivation; $4=$ responsible leadership + OCBE and autonomous motivation + external motivation; 5 = responsible leadership $+\mathrm{OCBE}+$ autonomous motivation + external motivation.

\subsection{Common Method Biases Test}

In this paper, the Harman single factor was used to test for common method bias. SPSS21.0 statistical analysis software was used for exploratory factor analysis. We factor all the variables into the factor analysis, the results show that a total of four factors with feature values greater than 1 were extracted, and the variance of the single factor with the largest feature values only explains $40.631 \%$, less than $50 \%$. there is no single factor or a common factor that plays a major role in explaining the variance. Therefore, the common method bias problem in this study is not serious [51,52].

\subsection{Descriptive Statistical Analysis}

Table 2 reports the mean, standard deviation and correlation coefficients of the variables involved in this study. There was a significant positive correlation between responsible leadership and autonomous motivation $(\mathrm{r}=0.293, p<0.01)$, external motivation $(\mathrm{r}=0.139, p<0.01)$ and OCBE $(\mathrm{r}=0.196, p<0.01)$. There was also a significant positive correlation between OCBE and autonomous motivation $(\mathrm{r}=0.487, p<0.01)$ and external motivation $(\mathrm{r}=0.505, p<0.01)$.

Table 2. Mean, Standard Deviation and Correlation.

\begin{tabular}{ccccccccc}
\hline Variable & $\mathbf{M}$ & SD & $\mathbf{1}$ & $\mathbf{2}$ & $\mathbf{3}$ & $\mathbf{4}$ & $\mathbf{5}$ & $\mathbf{6}$ \\
\hline 1. Gender & 1.51 & 0.501 & & & & & \\
2. Age & 2.56 & 0.909 & $-0.173^{* *}$ & & & & \\
3. Organizational tenure & 2.87 & 1.149 & $-0.102^{*}$ & $0.839 *$ & & & & \\
4. Education & 2.91 & 0.820 & $-0.141^{* *}$ & -0.075 & $-0.201^{* *}$ & & & \\
5. RL & 3.618 & 0.647 & 0.061 & 0.044 & 0.070 & -0.058 & & \\
6. AM & 3.672 & 0.644 & $0.116^{*}$ & -0.012 & 0.029 & -0.007 & $0.293^{* *}$ \\
7. EM & 2.782 & 0.793 & -0.024 & 0.054 & 0.052 & $-0.130^{*}$ & $0.139^{* *}$ & $0.348^{* *}$ \\
8. OCBE & 3.265 & 0.711 & 0.019 & $0.179 *$ & 0.154 & 0.068 & $0.196^{* *}$ & $0.487^{* *}$ \\
\hline
\end{tabular}

Note: $\mathrm{N}=384 ;{ }^{*}$ means $p<0.05,{ }^{* *}$ means $p<0.01$, and ${ }^{* * *}$ means $p<0.001 ; \mathrm{RL}=$ responsible leadership; $\mathrm{AM}=$ autonomous motivation; $\mathrm{EM}=$ external motivation. 


\subsection{Hypothetical Test}

We first used hierarchical regression analysis to test the positive influences of responsible leadership on autonomous motivation, external motivation and OCBE. Then, we used a structural equation model to test the dual mediating roles of autonomous motivation and external motivation between responsible leadership and OCBE (Table 3).

Table 3. Results of Hierarchical Regression Analyses.

\begin{tabular}{ccccc}
\hline Variable & Autonomous Motivation & External Motivation & \multicolumn{2}{c}{ OCBE } \\
\cline { 2 - 5 } & Model 2 & Model 3 & Model 1 & Model 4 \\
\hline Control variable & $0.103^{*}$ & -0.043 & 0.033 & 0.013 \\
Gender & 0.082 & 0.071 & $0.201^{*}$ & 0.146 \\
Age & -0.106 & -0.048 & -0.033 & 0.022 \\
Organizational tenure & 0.010 & $-0.132^{*}$ & -0.044 & 0.001 \\
Education & $0.291^{* * *}$ & $0.135^{* *}$ & $0.185^{* * *}$ & 0.033 \\
Independent variable & & & & $0.349^{* * *}$ \\
Responsible leadership & & & & $0.371^{* * *}$ \\
Mediator & $0.099^{* * *}$ & $0.038^{* * *}$ & $0.071^{* * *}$ & $0.393^{* * *}$ \\
Autonomous motivation & & & & $0.322^{* * *}$ \\
External motivation & $\mathrm{R}^{2}$ & & & \\
$\Delta \mathrm{R}^{2}$ & & & & \\
\hline
\end{tabular}

Note: $\mathrm{N}=384$; $^{*}$ indicates $p<0.05,{ }^{* *}$ indicates $p<0.01$, and ${ }^{* * *}$ indicates $p<0.001$; The regression coefficient is standardized regression coefficient.

The results of Model 1 (Table 3) indicate that after controlling for demographic variables, such as age and gender, responsible leadership has a significantly positive impact on OCBE $(\beta=0.185$, $p<0.001$ ), which supports $\mathrm{H}_{1}$. According to Model 3, after controlling for demographic variables, responsible leadership has a significantly positive impact on employee intrinsic motivation $(\beta=0.291$, $p<0.001$ ), which supports $\mathrm{H}_{2 \mathrm{a}}$. According to Model 3, after controlling for demographic variables, responsible leadership has a significantly positive impact on employee extrinsic motivation $(\beta=0.135$, $p<0.001$ ), which supports $\mathrm{H}_{3 \mathrm{a}}$.

According to Model 4, when responsible leadership, autonomous motivation and external motivation were simultaneously included in the regression equation of OCBE, the effect of responsible leadership on OCBE was not significant $(\beta=0.033, p>0.05)$. To more accurately test the dual mediating roles of autonomous and external motivations in OCBE, we constructed a dual-mediation model using a structural equation. The model fit was acceptable $\left(\chi^{2}(180)=562.259\right.$, IFI $=0.941$, $\mathrm{CFI}=0.941$, RMSA $=0.074$ ).

As shown in Figure 2, this study assumes that the transmission of the impact of responsible leadership to OCBE follows this path: responsible leadership $\rightarrow$ autonomous motivation $\rightarrow$ OCBE and responsible leadership $\rightarrow$ external motivation $\rightarrow$ OCBE. The coefficients between links in the transmission path are significant: responsible leadership $\rightarrow$ autonomous motivation $(\beta=0.321$, $p<0.001)$, autonomous motivation $\rightarrow \operatorname{OCBE}(\beta=0.0 .369, p<0.001)$, responsible leadership $\rightarrow$ external motivation $(\beta=0.148, p<0.001)$, and external motivation $\rightarrow \operatorname{OCBE}(\beta=0.443, p<0.001)$.To ensure the stability and consistency of the results, this study performs bootstrapping with 2,000 iterations for bias correction to verify the mediating role of autonomous and external motivation between responsible leadership and OCBE. 


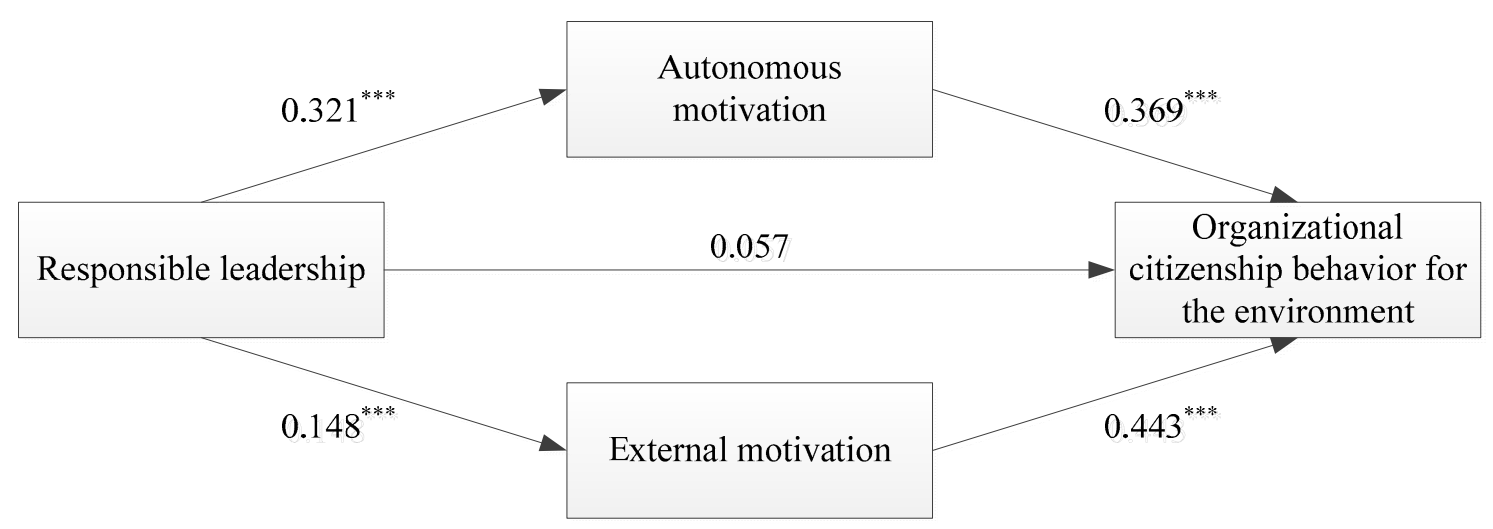

Figure 2. Path Coefficients. ${ }^{* * *}$ means $p<0.001$.

The results indicate that the mediating effect of autonomous motivation and external motivation is respectively 0.118 and 0.066 . For the mediating effect of the indirect path, the $95 \%$ confidence interval does not include zero [0.084, 0.310]. Therefore, the mediating role of autonomous motivation and external motivation between responsible leadership and OCBE is established, and hypothesis $\mathrm{H}_{2 \mathrm{~b}}$ and $\mathrm{H}_{3 \mathrm{~b}}$ is verified.

Because the direct effect of responsible leadership on OCBE was no longer significant $(\beta=0.0057$, $p>0.05$ ), intrinsic motivation and extrinsic motivation completely mediated the relationship between responsible leadership and OCBE, whereby the mediating effect accounted for $70 \%$ of the total effect.

\section{Conclusions and Discussion}

\subsection{Conclusions}

Responsible leadership, an emerging leadership style, has effectively compensated for the shortcomings of traditional leadership forms and is of substantial significance to enhancing corporate reputation and maintaining the sustainable development of enterprises and society [20]. According to stakeholder theory, responsible leadership combines corporate social responsibility and leadership ethics. On the one hand, responsible leadership establishes moral examples and inspires employees to imitate such examples by ethical behavior and avoiding image-damaging behavior. On the other hand, responsible leadership reflects requirements regarding corporate social responsibility. Therefore, in directing tasks related to corporate environmental responsibility, by demonstrating environmental friendliness, the leadership exerts a subtle effect on employee attitudes and behaviors. It encourages employees to engage in environmental protection through interacting with them, thus influencing employee motivation. In this study, we performed a regression analysis on data collected from 384 employees and drew the following conclusions. After controlling for gender, age, education and work experience, responsible leadership has a significantly positive impact on OCBE. Intrinsic and extrinsic motivations play a mediating role between responsible leadership and OCBE, whereby the mediating role of intrinsic motivation is greater than that of extrinsic motivation. Finally, the role of intrinsic motivation is greater than that of extrinsic motivation.

\subsection{Theoretical Significance}

OCBE refers to the environmental protection behavior of employees that is not rewarded or required by their organization's formal reward system. Thus, it primarily consists of discretionary environmental protection behavior by employees and represents an effective supplement to the daily environmental protection behavior of society at large and the green development strategies of the enterprise [8]. In this study, we investigated the effect of responsible leadership on OCBE and its internal mechanism. We sought to answer the question "How does responsible leadership affect the environmental protection behavior of subordinates" from the perspective of social learning theory. 
Our study results enrich the literature. According to social learning theory, the complex behavior of human beings is primarily acquired through learning, which includes both direct empirical learning modes and indirect learning modes in which individuals learn by observing the behavior of demonstrators [53]. Because leadership and employees often interact, the leadership's behavior affects employee attitudes and behaviors. It has been found that ethical leadership enhances OCBE through exemplary moral conduct and ethical atmosphere improvement [12]. Norton et al. (2015) called for more research attention on leadership styles that are closely related to green concepts [54]. Responsible leadership is concerned about not only internal stakeholders, such as employees but also external stakeholders with a wide range of connections with the enterprise and for whom the natural environment represents an important interest [19]. In this study, we examined the relationship between responsible leadership and employee environmental protection behavior. In addition, we investigated and verified the positive role of responsible leadership in encouraging employee environmental protection behavior through a sense of responsibility. This research focus expands investigations on the effect of responsible leadership on employee attitudes and behavior. In addition, it views the antecedents of OCBE from a different perspective than the traditional perspective of the dual modes of leadership behavior.

Second, the study results also enrich the literature on the influence mechanism of responsible leadership with respect to OCBE. Previous studies on responsible leadership have focused on the direct impact of responsible leadership on employee attitudes and behavior $[19,26]$. In this study, we found that responsible leadership promotes OCBE through employee motivation. Whether the behavior of the leadership can cause employees to learn and imitate that behavior largely depends on the employees' motivation. In this study, we examined the effect of responsible leadership on employee environmental protection behavior from the two aspects of intrinsic motivation and extrinsic motivation. We found that responsible leadership can promote OCBE by increasing the employees' motivation to engage in environmental protection. This outcome provides strong evidence for investigating the influencing mechanism of responsible leadership on OCBE.

\subsection{Management Implications}

To help resolve environmental problems, enterprises should adopt the philosophy of sustainable development and encourage employees to engage in more environmental protection behavior. Therefore, it is particularly important to improve employees' active environmental protection behavior. In this study, we found that responsible leadership exerts a promotive effect on employee intrinsic and extrinsic motivations to engage in environmental protection, which in turn promotes OCBE. The results of this study have the following management implications. (1) The role of responsible leadership in the sustainable development of the enterprise should be emphasized. In an organization, the manager's environmental ethics and a sense of corporate social responsibility affect employee environmental attitudes and practices. Thus, improving the level of the manager's responsible leadership and strengthening the manager's interaction with employees are conducive to promoting employee workplace environmental protection practices. Additionally, the organization's human resources practices should reflect a desire to recruit and hire individuals who exhibit the values and characteristics of responsible leadership. To strengthen the organization's responsible leadership, such values should be expressed in promotion decisions, training and leadership development. (2) Employee motivations affect whether they take the initiative to engage in environmental protection. In the organization, to improve OCBE, it is necessary to fully inspire their motivation to engage in environmental protection. Responsible leadership is leadership that promotes employee motivations to engage in environmental protection. Such leadership fully respects the employees and is concerned about their interests and those of other stakeholders. This attitude causes employees to experience a sense of autonomy while encouraging their environmental protection behavior. Therefore, the organization should train managers to improve their level of responsible leadership and strengthen 
their ability to trigger employee motivation to engage in environmental protection, thus promoting their OCBEs.

\subsection{Research Limitations and Future Directions}

Although this study offers a number of contributions to the literature, it has several limitations. First, the measurement of responsible leadership is derived from scales developed by investigators outside China. Although the scales have good reliability and validity, the conceptual connotation of responsible leadership and its validation for different cultures, including the Chinese context, require further investigation. Second, this study primarily discusses the influencing mechanism of responsible leadership on OCBE. It does not address conditions that may restrict this mechanism. Future researchers should examine whether different situations or employee characteristics can affect this mechanism. E.g., what is the effect of the organization's green human resources management and employee environmental awareness on the relationship between responsible leadership and OCBE? OCBE reflects the current appeal of environmental protection and resource conservation in Chinese society. Locally adapted OCBE can develop and expand in the context of China and has realized its values in Chinese circumstances through diversified localization explorations [55]. Therefore, in future studies, variables from the Chinese context should be included. Last, in this study, the analyzed data were primarily collected using employee self-evaluation. Responsible leadership was not assessed through the leaders' self-evaluation. It remains unclear whether responsible leadership according to employees and responsible leadership according to leaders differ. In future studies, we will examine the effect of responsible leadership defined according to the leaders' self-evaluation on OCBE.

Author Contributions: Z.H. coordinated the project and drafted this paper; Q.W. provided conceptual comments and contributed to revising the article; X.Y. contributed to data collection and analysis.

Funding: This research was funded by the Humanities and Social Sciences Research Fund of Anhui Province Department of Education (SK2017A0849) and National social science fund of China(18BGL129).

Conflicts of Interest: The authors declare no conflict of interests.

\section{References}

1. Bansal, P.; Song, H.-C. Similar but not the same: Differentiating corporate responsibility from sustainability. Acad. Manag. Ann. 2017, 11, 105-149. [CrossRef]

2. Starik, M.; Marcus, A.A. Introduction to the special research forum on the management of organizations in the natural environment: A field emerging from multiple paths, with many challenges ahead. Acad. Manag. J. 2000, 43, 539-547.

3. Starik, M.; Rands, G.; Marcus, A.A.; Clark, T.S. From the guest editors: In search of sustainability in management education. Acad. Manag. Learn. Educ. 2010, 9, 377-383.

4. Tang, G.Y.; Sun, W.; Jia, J.; Cheng, Y. A Literature Review of Green Human Resource Management and Future Prospects. Foreign Econ. Manag. 2015, 37, 82-96.

5. Starik, M.; Stubbs, W.; Benn, S. Synthesising environmental and socio-economic sustainability models: A multi-level approach for advancing integrated sustainability research and practice. Australas. J. Environ. Manag. 2016, 23, 402-425. [CrossRef]

6. Galpin, T.; Whittington, J.L. Sustainability leadership: From strategy to results. J. Business Strateg. 2012, 33, 40-48.

7. Felin, T.; Foss, N.J.; Ployhart, R.E. The Microfoundations Movement in Strategy and Organization Theory. Acad. Manag. Ann. 2015, 9, 575-632. [CrossRef]

8. Daily, B.F.; Bishop, J.W.; Govindarajulu, N. A conceptual model for organizational citizenship behavior directed toward the environment. Business Soc. 2009, 48, 243-256. [CrossRef]

9. Ramus, C.A.; Steger, U. The roles of supervisory support behaviors and environmental policy in employee "ecoinitiatives" at leading-edge European companies. Acad. Manag. J. 2000, 43, 605-626.

10. Lamm, E.; Tosti-Kharas, J.; King, C.E. Empowering employee sustainability: Perceived organizational support toward the environment. J. Business Ethics 2015, 128, 207-220. [CrossRef] 
11. Paille, P.; Mejia-Morelos, J.H. Antecedents of pro-environmental behaviours at work: The moderating influence of psychological contract breach. J. Environ. Psychol. 2014, 38, 124-131. [CrossRef]

12. Zhang, J.L.; Chen, Y.F.; Liu, J. Ethical leadership and OCBE: The influence of pro-social motivation and self accountability. Acad. Manag. Proc 2016, 2016.

13. Paille, P.; Boiral, O.; Chen, Y. Linking environmental management practices and organizational citizenship behaviour for the environment: A social exchange perspective. Int. J. Hum. Resour. Manag. 2013, 24, 3552-3575. [CrossRef]

14. Temminck, E.; Mearns, K.; Fruhen, L. Motivating employees towards sustainable behavior. Business Strateg. Environ. 2015, 24, 402-412. [CrossRef]

15. Priyankara, H.P.R.; Luo, F.; Saeed, A.; Nubuor, S.A.; Jayasuriya, M.P.F. How Does Leader's Support for Environment Promote Organizational Citizenship Behavior for Environment? A Multi-Theory Perspective. Sustainability 2018, 10, 271. [CrossRef]

16. Xing, L.L.; Lin, Y.Y.; He, X.L.; Peng, J. Cognition-driven or Emotion-driven: A Two Path-way Model Linking Responsible Leadership to Employee Green Behavior. Hum. Resour. Dev. China 2017, 1, 31-40.

17. Guo, Y.X.; Su, Y. The Double-edged Sword Effect of Responsible Leadership on Subordianates' Organizational Citizenship Behavior. Res. Econ. Manag. China 2018, 39, 90-102.

18. Miska, C.; Hilbe, C.; Mayer, S. Reconciling Different Views on Responsible Leadership: A Rationality-Based Approach. J. Business Ethics 2014, 125, 349-360. [CrossRef]

19. Maak, T.; Pless, N.M. Responsible leadership in a stakeholder society: A relational perspective. J. Business Ethics 2006, 66, 99-115. [CrossRef]

20. Voegtlin, C.; Patzer, M.; Scherer, A.G. Responsible Leadership in Global Business: A New Approach to Leadership and Its Multi-Level Outcomes. J. Business Ethics 2012, 105, 1-16. [CrossRef]

21. Lawrence, P.R.; Pirson, M. Economistic and Humanistic Narratives of Leadership in the Age of Globality: Toward a Renewed Darwinian Theory of Leadership. J. Business Ethics 2015, 128, 383-394. [CrossRef]

22. Pless, N.M.; Maak, T.; Stahl, G.K. Developing Responsible Global Leaders through International Service-Learning Programs: The Ulysses Experience. Acad. Manag. Learn. Educ. 2011, 10, 237-260.

23. Voegtlin, C. What Does It Mean to Be Responsible? Addressing the Missing Responsibility Dimension in Ethical Leadership Research. Leadership 2016, 12, 581-608. [CrossRef]

24. Bandura, A. Social Foundations of Thought and Action: A Social Cognitive Theory; Prentice Hall: Englewood Cliffs, NJ, USA, 1986.

25. Lord, R.G.; Brown, D.J. Leadership, values, and subordinate self-concepts. Leadersh. Q. 2001, 12, $133-152$. [CrossRef]

26. Voegtlin, C. Development of a Scale Measuring Discursive Responsible Leadership. J. Bus. Ethics 2011, 98, 57-73. [CrossRef]

27. Doh, J.P.; Stumpf, S.A.; Tymon, W.G., Jr. Responsible Leadership Helps Retain Talent in India. J. Bus. Ethics 2011, 98, 85-100. [CrossRef]

28. Cheng, L.Q. Research on the Influence Mechanism of Responsible Leadership on Employee's Work Performance; Wuhan University of Science and Technology: Wuhan, China, 2014.

29. Doh, J.P.; Quigley, N.R. Responsible Leadership and Stakeholder Management: Influence Pathways and Organizational Outcomes. Acad. Manag. Perspect. 2014, 28, 255-274. [CrossRef]

30. Stahl, G.K.; de Luque, M.S. Antecedents of responsible leader behavior: A research synthesis, conceptual framework, and agenda for future research. Acad. Manag. Perspect. 2014, 28, 235-254. [CrossRef]

31. Deci, E.L.; Ryan, R.M. The "what" and "why" of goal pursuits: Human needs and the self-determination of behavior. Psychol. Inquiry 2000, 11, 227-268. [CrossRef]

32. Gagné, M.; Deci, E.L. Self-determination theory and work motivation. J. Organ. Behav. 2005, 26, 331-362. [CrossRef]

33. Judge, T.A.; Bono, J.E.; Erez, A.; Locke, E.A. Core self-evaluations and job and life satisfaction: The role of self-concordance and goal attainment. J. Appl. Psychol. 2005, 90, 257-268. [CrossRef] [PubMed]

34. Zhou, R.Y.; Long, L.R. The weakening effect of Self-Sacrificial Leadership on Team Destructive Conflict. Chin. J. Manag. 2016, 13, 1339-1348.

35. Bono, J.E.; Judge, T.A. Self-concordance at work: Towards understanding the motivational effects of transformational leaders. Acad. Manag. J. 2003, 46, 554-571. 
36. Jung, D.I.; Avolio, B.J. Opening the black box: An experimental investigation of the mediating effects of trust and value congruence on trans-formational and transactional leadership. J. Organ. Behav. 2000, 21, 949-964. [CrossRef]

37. Shamir, B.; Zakay, E.; Breinin, E.; Popper, M. Correlates of charismatic leader behavior in military units: Subordinates' attitudes, unit characteristics, and superiors' appraisals of leader performance. Acad. Manag. J. 1998, 41, 387-409.

38. Avolio, B.J.; Zhu, W.; Koh, W.; Bhatia, P. Transformational leadership and organizational commitment. J. Organ. Behav. 2004, 25, 951-968. [CrossRef]

39. Walumbwa, F.O.; Avolio, B.J.; Zhu, W. How transformational leadership weaves its influence on individual job performance: The role of identification and efficacy beliefs. Pers. Psychol. 2008, 61, 793-825. [CrossRef]

40. Ryan, R.M.; Deci, E.L. Self-determination theory and the facilitation of intrinsic motivation, social development, and well-being. Am. Psychol. 2000, 55, 68-78. [CrossRef]

41. Graves, L.M.; Sarkis, J.; Zhu, Q. How transformational leadership and employee motivation combine to predict employee pro-environmental behaviors in China. J. Environ. Psychol. 2013, 35, 81-91. [CrossRef]

42. Sheldon, K.M.; Elliot, A.J. Not all personal goals are personal: Comparing autonomous and controlled reasons for goals as predictors of effort and attainment. Pers. Soc. Psychol. Bull. 1998, 24, 546-557. [CrossRef]

43. Sheldon, K.M.; Elliot, A.J. Goal striving, need satisfaction, and longitudinal well-being: The self-concordance model. J. Pers. Soc. Psychol. 1999, 76, 482-497. [CrossRef] [PubMed]

44. Osbaldiston, R.; Sheldon, K.M. Promoting internalized motivation for environmentally responsible behavior: A prospective study of environmental goals. J. Environ. Psychol. 2003, 23, 349-357. [CrossRef]

45. Pelletier, L.G. A motivational analysis of self-determination for pro-environmental behaviors. In Handbook of Self-Determination Research; Deci, E.L., Ryan, R.M., Eds.; University of Rochester: Rochester, NY, USA, 2002; pp. 205-232.

46. Afsar, B.; Badir, Y.; Kiani, U.S. Linking spiritual leadership and employee pro-environmental behavior: The influence of workplace spirituality, intrinsic motivation, and environmental passion. J. Environ. Psychol. 2016, 45, 79-88. [CrossRef]

47. Bass, B.M. Transformational Leadership: Industry, Military, and Educational Impact; Erlbaum: Mahwah, NJ, USA, 1998.

48. Judge, T.A.; Piccolo, R.F. Transformational and transactional leadership: A meta-analytic test of their relative validity. J. Appl. Psychol. 2004, 89, 755-768. [CrossRef] [PubMed]

49. Andersson, L.; Shivarajan, S.; Blau, G. Enacting ecological sustainability in the MNC: A test of an adapted value-belief-norm frame work. J. Business Ethics 2005, 59, 295-305. [CrossRef]

50. Greenbaum, R.L.; Mawritz, M.B.; Mayer, D.M. To act out, to withdraw, or to constructively resist? Employee reactions to supervisor abuse of customers and the moderating role of employee moral identity. Hum. Relat. 2013, 66, 925-950. [CrossRef]

51. Eby, L.T.; Dobbins, G.H. Collectivistic orientation in teams: An individual and group-level analysis. J. Organ. Behav. 1997, 18, 275-295. [CrossRef]

52. Livingstone, L.P.; Nelson, D.L.; Barr, S.H. Person-environment fit and creativity: An examination of supply-value and demand-ability version of fit. J. Manag. 1997, 23, 119-146. [CrossRef]

53. Bandura, A. Social Learning. In Blackwell Encyclopedia of Social Psychology; Wiley: Hoboken, NJ, USA, 1971.

54. Norton, T.A.; Parker, S.L.; Zacher, H.; Ashkanasy, N.M. Employee green behavior: A theoretical framework, multilevel review, and future research agenda. Organ. Environ. 2015, 28, 103-125. [CrossRef]

55. Zhang, J.L.; Liu, J. Organizational Citizenship Behavior for the Environment: A Literature Review and Prospects. Foreign Econ. Manag. 2016, 38, 35-48.

(C) 2019 by the authors. Licensee MDPI, Basel, Switzerland. This article is an open access article distributed under the terms and conditions of the Creative Commons Attribution (CC BY) license (http:/ / creativecommons.org/licenses/by/4.0/). 